\title{
COLORING OF $\mathrm{Bi}_{4} \mathrm{Ge}_{3} \mathrm{O}_{12}-\mathrm{Mn}$ CRYSTALS INDUCED BY ELECTRIC FIELD
}

\author{
T.M. Bochkova* \\ Oles Honchar Dnipro National University, Dnipro, Ukraine \\ *e-mail: tbochkova@meta.ua
}

\begin{abstract}
The effect of the direct electric field on the optical transmittance of $\mathrm{Bi}_{4} \mathrm{Ge}_{3} \mathrm{O}_{12}$ single crystals doped with $\mathrm{Mn}$ is studied in the mode of using asymmetric contacts when only one electrode (Ag or In-Ga) is injected. It is found that changes in the optical transmittance spectra under the action of unipolar injection of electrons and holes are different. They also differ from the case of using symmetrical electrodes (double injection mode). The optimal temperature and field conditions for electrochromic coloring are determined from the correspondence between the manifestations of the electrochromic effect in $\mathrm{Bi}_{4} \mathrm{Ge}_{3} \mathrm{O}_{12}-\mathrm{Mn}$ crystals and the current-voltage characteristics. It is shown that the maximum effect is achieved by injecting holes into a $\mathrm{Bi}_{4} \mathrm{Ge}_{3} \mathrm{O}_{12}-\mathrm{Mn}$ sample annealed in a reducing atmosphere.

Keywords: $\mathrm{Bi}_{4} \mathrm{Ge}_{3} \mathrm{O}_{12}$, electrocromic effect, current-voltage relations, injection of charge carriers.
\end{abstract}

Received 23.06.2021; Received in revised form 25.07.2021; Accepted 15.08.2021

\section{Introduction}

Crystals of bismuth orthogermanate $\left(\mathrm{Bi}_{4} \mathrm{Ge}_{3} \mathrm{O}_{12}, \mathrm{BGO}\right)$ are widely used in technology. High quality pure crystals are used to detect high energy ionizing radiation in dosimetry, tomography and expensive space projects [1]. In technologically advanced countries, large crystals are grown on an industrial scale [2]. Crystals doped with rare earths have unique spectral-generation properties and can be used as laser materials [3]. Doping with iron group elements makes it possible to use BGO in optical information processing systems as photorefractive materials [4]. The photochromic effect significantly increases the sensitivity BGO for recording of holographic diffraction gratings. It was shown in [5] that irradiation with UV light of BGO crystals with an impurity of Mn leads to recharging of active centers in the crystal lattice through redox reactions. Similar processes also occur during hightemperature annealing in oxidizing or reducing atmospheres [6]. Recently it was reported for the first time about changes in the spectrum of optical absorption of light of BGO-Mn under the influence of a direct electric field [5]. Thus, the electrochromic effect is also observed in BGO-Mn crystals. This article presents the results of further studies of electrochromism in bismuth orthogermanate.

\section{Samples and experimental details}

The crystals of BGO doped with Mn were grown from the melt by Czochralski method using double recrystallization technology. The $\mathrm{Mn}$ content in the crystals according to spectral analysis was 0.01-0.03 weight\%. Annealing of the crystal samples in a stream of hydrogen was carried out in a quartz furnace at 1225-1275 K during 48 hours and then the samples were cooled with a rate $\sim 10 \mathrm{~K} / \mathrm{h}$.

The optical transmittance spectra were measured using a "Specord - UV-VIS" spectrophotometer at $295 \mathrm{~K}$.

Electrochromic coloring of BGO-Mn single crystals in the unipolar injection mode was studied on the plane polished samples with two asymmetric electrodes in the longitudinal geometry of the experiment. Ag or In-Ga were chosen as the metal of the injection electrode. In order to avoid double injection of charge carriers, a thin layer of silicate glass $\left(\mathrm{Na}_{2} \mathrm{SiO}_{3}\right)$ was applied between the sample and the electrode on the other side of the sample similarly to the experiments described in $[7,10]$. The electric field $(3 \mathrm{kV} / \mathrm{cm})$ was applied at $600 \mathrm{~K}$ during $1 \mathrm{~h}$. After cooling of the sample the electrodes were removed and optical transmittance of the samples was measured. 


\section{Results and discussion}

The effect of BGO-Mn coloration induced by the electric field was discovered and investigated in [5]. Ag electrodes were deposited on wide faces of samples $\sim 2 \mathrm{~mm}$ thick, a field of $0-3 \mathrm{kV} / \mathrm{cm}$ was applied at a fixed temperature in the range of 300-600 K for 1 hour. After cooling the sample under the action of the field, the electrodes were washed off with an aqueous solution of nitric acid, and the optical transmittance spectrum was recorded. The existence of temperature and field dependences of coloring is revealed. The magnitude of the applied field was limited by the sample thickness required for reliable measurement of changes in optical spectra. An increase in voltage led to electrical breakdown of the samples.

Measurements in longitudinal geometry of the experiment showed the appearance of the broad absorption bands of light with maxima at 13500, 25000, and $30000 \mathrm{~cm}^{-1}$ with an increase of the applied field. Measurements were also carried out in the transverse geometry of the experiment, i.e. when the light beam passed perpendicular to the applied field. In the central part of such samples, an increase in light transmittance relative to the initial spectrum was observed. To understand the nature of the electrochromic effect in BGO-Mn, one should consider its electrical properties.

BGO crystals are high-resistance and heavily compensated semiconductors (band gap $\mathrm{E}_{\mathrm{g}}>4.5 \mathrm{eV}$, dark conductivity at room temperature $\sigma \sim 10^{-13} \mathrm{Ohm}^{-1} \cdot \mathrm{m}^{-1}$ ) [7-8]. It was found that both electrons and holes are mobile charge carriers in the range 300-700 K. Conduction is of a hopping nature. The electrical properties of BGO indicate that it belongs to relaxation semiconductors. It is characterized by very low values of the drift mobility and concentration of mobile charge carriers, an activation increase in mobility and conductivity with temperature, an increase in conductivity with the frequency of an alternating field according to a power law.

The study of the current-voltage characteristics of BGO showed that double injection of charge carriers is observed in the samples of crystals with electrodes of $\mathrm{Ag}$, $\mathrm{Pt}, \mathrm{In}-\mathrm{Ga}$ [8]. Since electrons are the majority carriers in the room temperature region, the injection of electrons leads to the formation of an electron-enriched space charge. In the region $450-575 \mathrm{~K}$ the hole injection becomes noticeable and the current through the sample is limited by recombination processes. It was shown in [9] that in BGO-Mn crystals, a manganese impurity takes part in the recombination process. This is also confirmed by I - V relations measured on BGO-Mn samples in the mode of the unipolar injection [10].

It is logical to assume that the electrochromic effect in BGO-Mn crystals is due to the recharging of active local centers in the crystal lattice under the action of an electric field and is associated precisely with the processes of injection of charge carriers into the sample. In the temperature region of existence of double injection of electrons and holes, we observe a general result in the longitudinal geometry of the experiment. Therefore, the coloring of BGO-Mn crystals in the unipolar injection mode is of considerable interest. The change in the optical transmittance spectra of BGO-Mn crystals under the action of injection of electrons and holes is shown in Fig. 1. As can be seen from the figure, the injection of holes leads to a decrease in the transmittance in the range of $32500-25000$ $\mathrm{cm}^{-1}$. Electron injection increases the transmittance in the range of $27000-14500 \mathrm{~cm}^{-1}$. A similar result, leading to bleaching of BGO-Mn samples, was observed after hightemperature annealing of crystals in a reducing atmosphere. Figure 2 shows the spectrum of crystal annealed in a $\mathrm{H}_{2}$ flow. According to [5-6], the Mn impurity, which can be in BGO-Mn in various valence states, after annealing in $\mathrm{H}_{2}$, is reduced to $\mathrm{Mn}^{2+}$. 


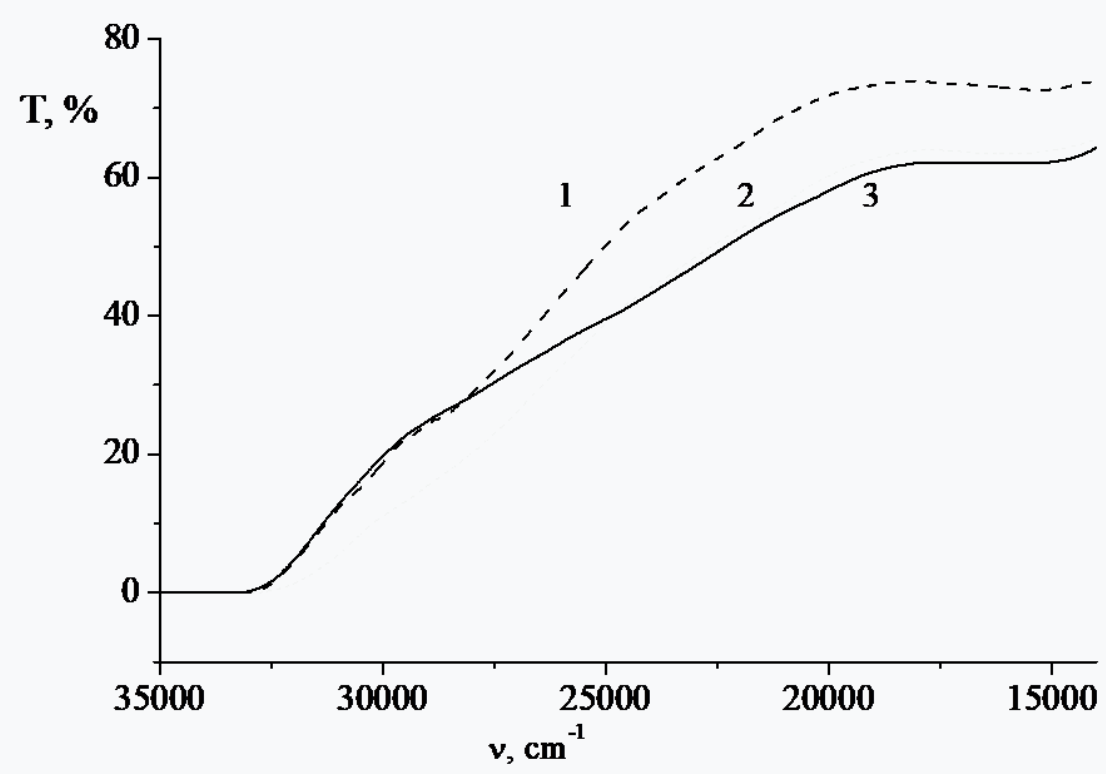

Fig. 1. The optical transmittance spectra of BGO-Mn crystals: initial (3) and colored by the electric field through unipolar injection of electrons(1) and holes (2) The thickness of the samples was $2.6 \mathrm{~mm}$.

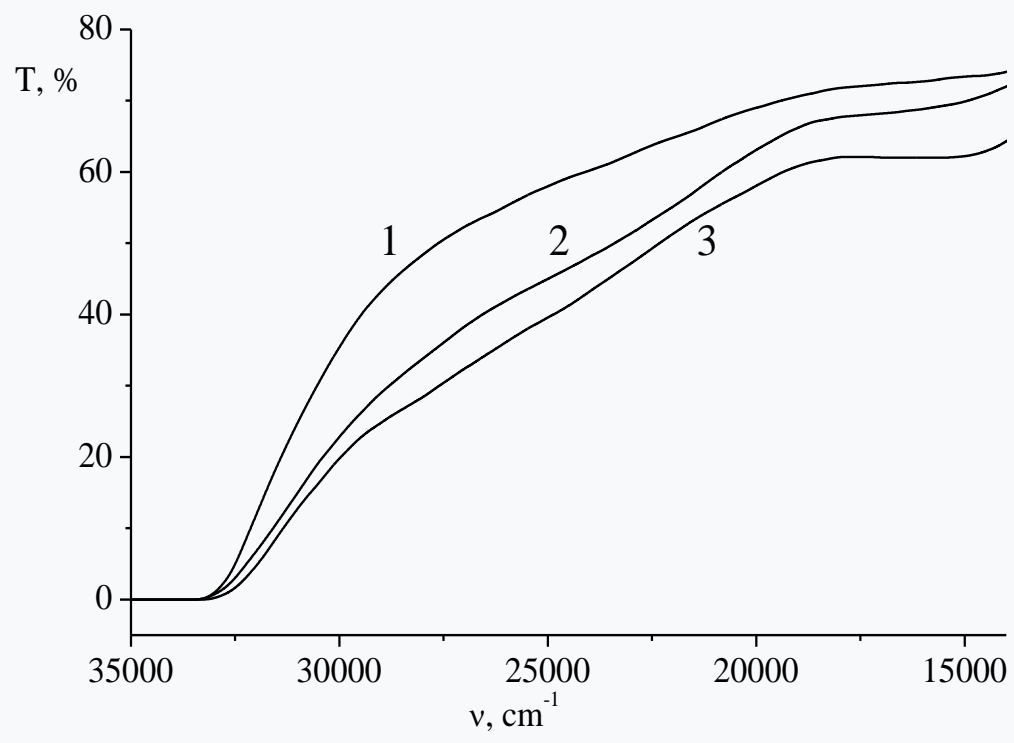

Fig. 2. The optical transmittance spectra of BGO-Mn crystals: 1 - annealed in $\mathrm{H}_{2}$; 2 - colored by the electric field through unipolar injection of holes; 3 - initial crystal. The thickness of the samples was $2 \mathrm{~mm}(1,2)$ and $2.6 \mathrm{~mm}(3)$.

All absorption bands in the optical spectrum associated with the presence of $\mathrm{Mn}^{3+} \mathrm{Mn}^{4+}$ and, possibly, defects caused by oxidation of bismuth ions disappear. It is obvious that the injection of electrons into the sample leads to the same result. It can be assumed that the maximum optical transmittance contrast can be achieved by injecting holes into a 
BGO-Mn crystal annealed in a reducing atmosphere. The result of such an experiment is also shown in Fig. 2. The spectrum of the initial BGO-Mn crystal, which has not undergone any manipulations, but has a slightly greater thickness, is also given in Fig. 2 for comparison.

\section{Conclusions}

The existence of a Mn impurity in the BGO crystal lattice in various valence states and the related need for charge compensation causes a number of optical absorption bands in the spectra. Their intensity can be changed by high-temperature annealing in different atmospheres, UV irradiation (photochromic effect) and direct electric field (electrochromic effect). The paper shows the influence of unipolar injection of electrons and holes on the optical transmittance of BGO-Mn, and establishes a correlation between the data obtained and measurements of the current-voltage characteristics.

\section{References}

1. Takahashi, H. Data acquisition system and ground calibration of polarized gamma-ray observer (PoGOLite) / H. Takahashi, M. Chauvin, Y. Fukazawa et al // Proceedings of the SPIE. - 2014. - V. 9144, id. 91444I 7.

2. Borovlev, Yu.A. Progress in growth of large sized BGO crystals by the lowthermal-gradient Czochralski technique / Yu.A Borovlev, N.V Ivannikova, V.N Shlegel, Ya.V Vasiliev, V.A.Gusev // J. Cryst. Growth. - 2001. - Vol. 229, No. 1-4. - P. 305 311.

3. Kaminskiy, A.A. Polarizatsionnye magnitoopticheskie effekty $\mathrm{v}$ nepreryvnom $\mathrm{Nd}^{3+}: \mathrm{Bi}_{4} \mathrm{Ge}_{3} \mathrm{O}_{12}$ - lazere $(\lambda=1,06425$ и $1,3418 \mathrm{mkm})$ s poluprovodnikovoy nakachkoy / A.A. Kaminskiy, N.V. Kravtsov, N. I. Naumkin i dr. // Kvantovaya elektronika. - 2000. V. 30, № 4 - P. 283-284 (in Russian).

4. Marinova, V. Optical and holographic properties of $\mathrm{Fe}+\mathrm{Mn}$ co-doped $\mathrm{Bi}_{4} \mathrm{Ge}_{3} \mathrm{O}_{12}$ crystals / V. Marinova, D. Petrova, Shiuan Huei Lin, Ken Yuh Hsu //Optics Communs. 2008. - Vol. 281. - P. 37-43.

5. Bochkova, T.M. Color centers in $\mathrm{Mn}$ - doped $\mathrm{Bi}_{4} \mathrm{Ge}_{3} \mathrm{O}_{12}$ single crystals / T.M. Bochkova // Visnyk DNU, Ser. Fizika. Radioelectronika. - 2014. - Vol. 22, No 1(21). - P. $119-124$.

6. Bochkova, T.M. High- temperature annealing of $\mathrm{Mn}$-doped $\mathrm{Bi}_{4} \mathrm{Ge}_{3} \mathrm{O}_{12}$ single crystals //Visnyk DNU. - 2016. - Vol. 24. - № 23. - P. 114-118.

7. Bochkova, T.M. Unipolar injection currents in $\mathrm{Bi}_{4} \mathrm{Ge}_{3} \mathrm{O}_{12}$ single crystals / T.M. Bochkova, S.N. Plyaka, G.Ch. Sokolyanskii.// Semiconduct. Physics, Quant. Electronics and Optoelectronics. - 2003. - Vol. 6. - No4. - P. 461- 464.

8. Bochkova,T.M. Charge transport in bismuth orthogermanate crystals / T.M. Bochkova, S.N. Plyaka // Semiconduct. Physics, Quant. Electronics and Optoelectronics. - 2011. - Vol. 14, No2. - P. 170-174.

9. Bochkova, T.M. Formuvannya prostorovyh zaryadiv u kristalah $\mathrm{Bi}_{4} \mathrm{Ge}_{3} \mathrm{O}_{12} /$ T.M. Bochkova, S.N. Plyaka.// Visnyk DNU, Ser. Fizika. Radioelectronika. - 2012. Vol.20, No2. - 2012. - P. 119 - 124 (in Ukranian).

10. Bochkova, T.M. $\mathrm{I}-\mathrm{V}$ characteristics of $\mathrm{Bi}_{4} \mathrm{Ge}_{3} \mathrm{O}_{12}-\mathrm{Mn}$ crystals in the unipolar injection mode //J. Phys. Electron. -DNU.-2019.-V.27, Iss.2. - P.81-84. 